\title{
ELABORAÇÃO DE UM MAPA DE RUÍDO PARA A REGIÃo CENTRAL DA CIDADE DE CURITIBA - PR
}

\section{ELABORATION OF A NOISE MAP IN CURITIBA DOWNTOWN}

\author{
Eduardo Cantieri \\ Especialista em Engenharia de Segurança do Trabalho \\ Programa de Pós-Graduação em Engenharia Civil - UTFPR - Campus Curitiba \\ eduardo.cantieri@electrolux.com.br

\section{Rodrigo Eduardo Catai} \\ Professor Adjunto, Dr. \\ Programa de Pós-Graduação em Engenharia Civil - UTFPR - Campus Curitiba \\ catai@utfpr.edu.br \\ Rafael Antonio Agnoletto \\ Mestrando em Engenharia Civil \\ Programa de Pós-Graduação em Engenharia Civil - UTFPR - Campus Curitiba \\ rafengenheiro@hotmail.com

\section{Hugo Flávio Benassi Zanqueta} \\ Mestrando em Engenharia Mecânica \\ Universidade Federal de Santa Catarina \\ hugo.zanqueta@electrolux.com.br

\section{Arildo Dirceu Cordeiro} \\ Professor Adjunto, Dr. \\ Programa de Pós-Graduação em Engenharia Civil - UTFPR - Campus Curitiba \\ arildo@utfpr.edu.br

\section{Cezar Augusto Romano} \\ Professor Adjunto, Dr. \\ Departamento Acadêmico de Construção Civil - UTFPR - Campus Curitiba \\ caromano@utfpr.edu.br
}




\title{
RESUMO
}

Neste trabalho foi criado um mapa de ruído do centro da cidade de Curitiba, no qual são apresentados os níveis de ruído medidos em 55 pontos distintos. Esta ferramenta gráfica tem o objetivo de tornar mais clara a visualização dos níveis de ruído presentes nas diferentes ruas da cidade. As medições dos níveis de ruído foram feitas com um medidor de pressão sonora no horário compreendido entre 17:00 horas e 19:00 horas. Os resultados encontrados foram comparados com as normas vigentes. Todos os 55 pontos medidos apresentaram níveis de ruído superiores ao valor limite estabelecido por uma lei municipal. A ferramenta criada mostrou-se interessante, pois é de fácil confecção e utilização.

Palavras-chave: Ruído; Trânsito; Mapa de ruído.

\begin{abstract}
In this paper was developed a noise map of Curitiba downtown. In this map were measured 55 different points. This graphical tool has the objective of show clearly the noise levels in Curitiba downtown. The measurements were made with a noise level meter between 17:00 and 19:00 hours. The results were compared with the standards. All 55 points had measured noise levels exceed the value established by a municipal law. The tool created is interesting because it is easy to manufacture and use.
\end{abstract}

Key-words: Noise; Traffic; Noise map.

\section{INTRODUÇÃO}

No meio dos diversos incômodos existentes na vida urbana como trânsito, poluição atmosférica e visual, encontra-se a poluição sonora. Presente nas ruas e causada principalmente por fontes de ruído como meios de transporte, indústrias e canteiros de obras, esta poluição pode causar alterações comportamentais e orgânicas nos seres humanos. Dores de cabeça, estresse, depressão, agressividade, cansaço são efeitos comuns da ação da poluição sonora sobre os seres humanos.

Segundo a World Health Organization (2003), a poluição sonora é hoje, depois da poluição do ar e da água, o problema ambiental que afeta o maior número de pessoas, o que conseqüentemente altera os sentidos e a forma de se relacionar com o mundo e com as outras pessoas, já que os sujeitos incorporam as experiências que são vivenciadas diariamente. Ocorrem, a partir do aumento do ruído, alterações nas reações psíquicas como, por exemplo, a 


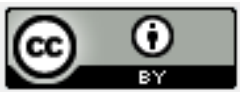

motivação, nervosismo, a agressividade, a capacidade de aprendizagem e de concentração; influenciando diretamente na qualidade de vida dos indivíduos moradores de zonas urbanas.

Este tipo de poluição é provocado pelo ruído excessivo das indústrias, canteiros de obras, meios de transporte, áreas de recreação, tráfego de veículos, uso irresponsável de megafones e propagandas em carros de som, entre outros. Estes ruídos provocam efeitos negativos para o sistema auditivo das pessoas, além de provocar alterações comportamentais e orgânicas. Dentre os efeitos negativos destacam-se: a insônia, a dificuldade de dormir, o estresse, a depressão, a perda auditiva, o aumento da agressividade, a dificuldade de concentração, a perda de memória, dores de cabeça, o aumento da pressão arterial, o cansaço, gastrites, úlceras e a diminuição do rendimento escolar e no trabalho.

Em busca de uma amenização para este problema, iniciou-se na União Européia um programa de mapeamento de ruído das cidades que consiste na medição do nível de ruído nas ruas, com o posicionamento do medidor de pressão sonora a uma determinada altura do solo. Após mapeamento da zona em questão é possível identificar áreas com níveis sonoros acima dos permitidos bem como as fontes emissoras destes ruídos, monitorar a emissão causada por máquinas e processos, identificar zonas dentro dos limites aceitáveis evitando assim medidas desnecessárias para a área e propor medidas de atenuação para as áreas críticas.

Como esta técnica proporciona a construção de um plano de ação para controle do ruído, ela acaba sendo também uma importante ferramenta econômica para evitar o desperdício de dinheiro com ações de prevenção em área indevidas, além de seu uso possibilitar uma melhoria da qualidade de vida para cidadãos e das condições de trabalho para aqueles que têm suas vidas profissionais nos grandes centros urbanos.

Este artigo tem como objetivo a elaboração do mapa de ruído de uma área do centro da cidade de Curitiba para análise dos níveis de ruído em que estão expostos os cidadãos e trabalhadores como garis e vendedores ambulantes e, conseqüentemente, identificar áreas com níveis sonoros acima dos permitidos pelas Normas Regulamentadoras e Leis Municipais. Isto possibilita uma avaliação posterior para utilidade não só dos trabalhadores como também para avaliação de compra e venda do mercado imobiliário, visto que o ruído é visto como incômodo para edificações com fins residenciais. 


\section{REVISÃO BIBLIOGRÁFICA}

Segundo Gerges (1992), o som se caracteriza por flutuações de pressão em um meio compressível. Entretanto, não são todas as flutuações de pressão que produzem a sensação de audição quando atingem o ouvido humano. Essa sensação de som só ocorrerá quando a amplitude destas flutuações e a freqüência com que elas se repetem estiverem dentro de certos limites de valores. Desta forma, flutuações de pressão com amplitudes inferiores a certos limites mínimos não serão audíveis, assim como ondas de altas intensidades podem produzir uma sensação de dor, ao invés de som.

\subsection{Ruído}

De acordo com Grandjean (1998), certos sons não afetam ou perturbam as pessoas até um certo limite, porém quando elevados, tornam-se perturbadores e incômodos, passando a ser definidos como ruído. Um indivíduo exposto a níveis de ruído indesejáveis pode apresentar efeitos negativos em sua saúde como: estresse, depressão, perda de audição, etc.

Segundo Belojevic et al. e Maschke apud Zanin e Szeremetta (2003), o nível de pressão sonora excessivo é um fato comum nos grandes centros urbanos, gerado principalmente pelos meios de transporte. Seus estudos mostram que o ruído de tráfego de $66 \mathrm{~dB}(\mathrm{~A})$ é considerado como o limiar do dano à saúde e, conseqüentemente, a medicina preventiva estabelece 65 $\mathrm{dB}(\mathrm{A})$ como o nível máximo a que um cidadão pode se expor no meio urbano, sem riscos .

Na definição de psicologia, encontrada em Lacerda et al. (2005), o homem se constitui no contexto físico e social, sendo dialeticamente modificado ao mesmo tempo em que contribui para o desenvolvimento deste ambiente. Desta forma, a construção da subjetividade humana, bem como os aspectos psicológicos implicados (percepção, ação, sensações etc) estão pautados em estímulos, nos quais se incluem o sonoro, existente dentro do ambiente no qual se vive.

O som se propaga, a partir de uma fonte, em forma de ondas esféricas, e esta propagação pode ser dificultada no caso da presença de um obstáculo na trajetória de propagação, ou não haja uniformidade do meio, causada por ventos e gradientes de temperaturas desiguais. O som nasce através de vibrações de superfícies sólidas que 


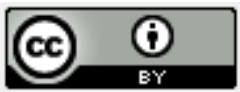

produzem excitações no ar. Então, qualquer processo que provoca flutuações no ar pode gerar ondas sonoras. A fonte sonora pode, portanto, ser representada por uma superfície vibrante (GERGES, 1992).

Moraes e Regazzi (2002) relatam que o som consiste em um agente físico causado por qualquer vibração ou onda mecânica que se propague em meio elástico, produzindo excitações auditivas ao homem. Ruído é uma mistura de sons cujas freqüências não seguem quaisquer leis precisas e que diferem entre si por valores imperceptíveis ao ouvido humano, considerando como um som indesejado.

Segundo Santos e Russo (1999), a acústica é a parte da física que se preocupa com o estudo do som, tanto em sua produção e transmissão, quanto na sua detecção pelo ouvido humano. Divide-se em acústica física (quando se trata do estudo puro das vibrações, ondas mecânicas e tem como principal objeto o som); e acústica fisiológica ou psicoacústica (parte da acústica relacionada à sensação que o som produz nos indivíduos, os julgamentos e impressões que eles emitem ao receberem uma estimulação sonora em seus ouvidos).

\subsubsection{A Orelha humana}

Caracterizado por ser um sistema muito sensível e complexo, a orelha humana permite perceber e interpretar os sons. A orelha ou órgão vestibulococlear é dividido em partes externa, média e interna, conforme Figura 1, e possui duas funções: equilíbrio e audição. As partes externa e média são relacionadas com a transferência de som para a orelha interna, que contém o órgão do equilíbrio e audição. A membrana timpânica separa a orelha externa da orelha média e a tuba auditiva une a orelha média à parte nasal da faringe (MOORE, 2001). 


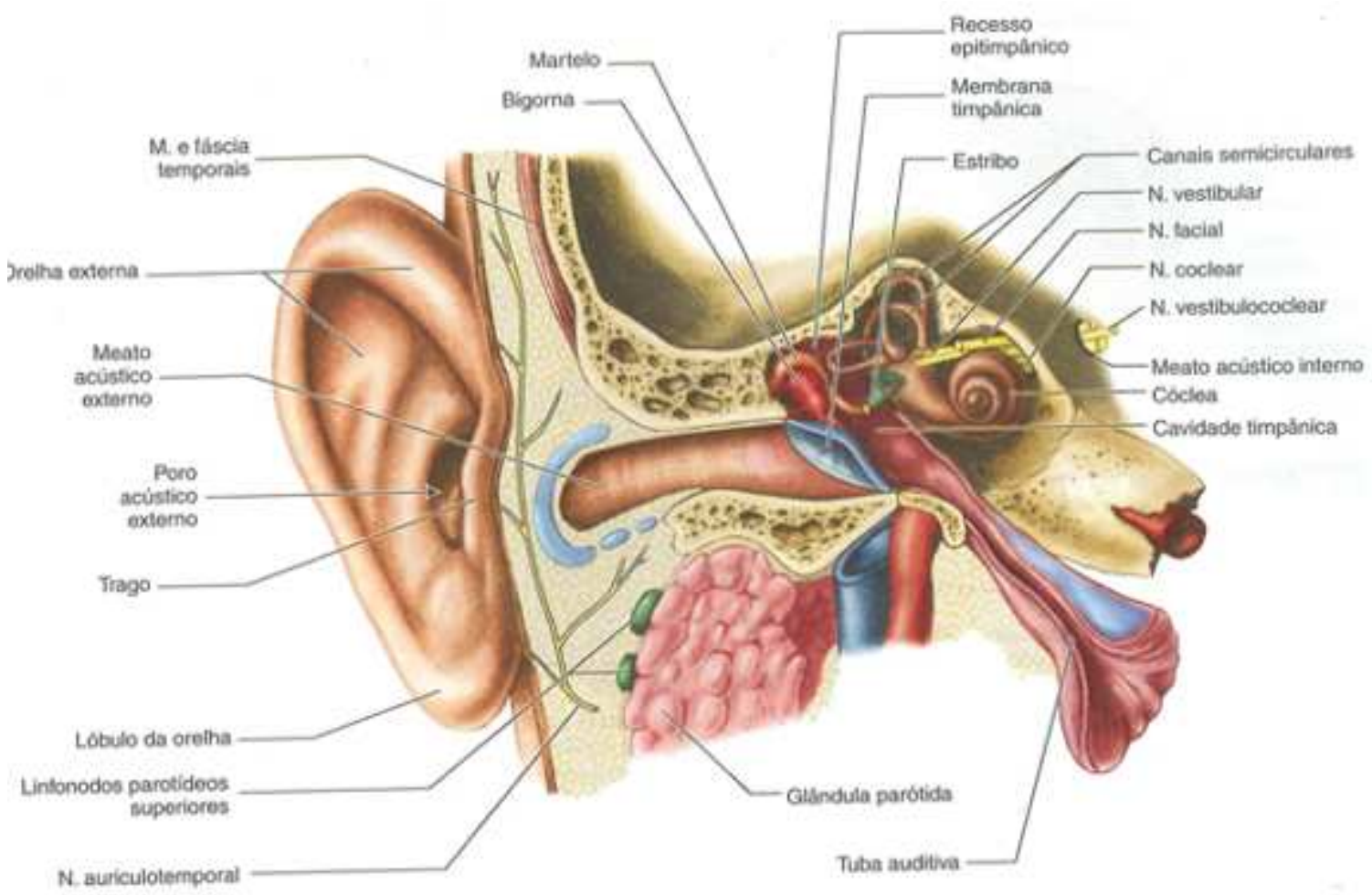

Figura 1 - Orelha Humana

Fonte: Moore (2001).

Ainda segundo Moore (2001), o limiar de audição, que é a pressão acústica mínima que o ouvido pode detectar é $20 \times 10^{-6} \mathrm{~N} / \mathrm{m}^{2}$ na freqüência de $1 \mathrm{kHz}$. Na banda de freqüência auditiva que vai de $20 \mathrm{~Hz}$ a $20.000 \mathrm{~Hz}$, a orelha não é igualmente sensível.

O ouvido humano responde a uma larga faixa de intensidade acústica, desde o limiar da audição até o limiar da dor. A intensidade acústica, a $1.000 \mathrm{~Hz}$, capaz de causar a sensação de dor é $10^{14}$ vezes a intensidade acústica capaz de causar sensação de audição. Devido à dificuldade de se expressar números de ordens de grandeza tão diferentes numa mesma escala linear, usa-se a escala logarítmica. Um valor adequado de divisão para esta escala seria log 10 o qual recebe-se o nome Bel. Como este é um valor muito grande de divisão de escala, usa-se então o decibel (dB) que é um décimo do Bel (GERGES, 1992). 


\subsubsection{Nível de pressão sonora}

A pressão sonora medida em decibel $(\mathrm{dB})$ é definida como nível de pressão sonora (NPS) e refere-se à relação logarítmica do quadrado da pressão sonora em questão com o quadrado da pressão sonora de referência. Matematicamente escreve-se de acordo com a Equação 1 e 2 (GERGES, 2000).

$$
\mathrm{NPS}=20 . \log \frac{\mathrm{P}}{\mathrm{P}_{\mathrm{ref}}}(\text { decibel }-d B)
$$

ou

$$
\mathrm{NPS}=\log \frac{\mathrm{P}}{\mathrm{P}_{\mathrm{ref}}}(\mathrm{Bel}-\mathrm{B})
$$

onde: $I$ a intensidade sonora de um som, e $P_{r e f}=20^{-6} \mathrm{~Pa}$.

\subsubsection{Leis e Normas Regulamentadoras quanto ao ruído}

O Ministério do Trabalho e Emprego faz uso de duas normas regulamentadoras para regulamentar os valores de ruído, a NR-15 que versa sobre insalubridade e a NR-17 sobre ergonomia. De acordo com a Norma Regulamentadora 15 - Atividades e Operações Insalubres, o Limite de Tolerância é a concentração ou intensidade máxima ou mínima, relacionada com a natureza e o tempo de exposição ao agente, que não causará dano à saúde do trabalhador. Desta forma ficam estabelecidos os limites de tolerância para ruído em função do nível de ruído e do tempo de exposição de acordo com a Tabela 1 (BRASIL, 2009a).

Já a NR-17 comenta que um valor limite para se ter conforto acústico dentro de um ambiente é de $65 \mathrm{~dB}(\mathrm{~A})$. A norma comenta também que os valores de ruído limites exigidos para cada ambiente podem ser encontrados na NBR 10152 (BRASIL, 2009b).

Quando se trata de ruído urbano na cidade de Curitiba a legislação a ser seguida deverá ser a Lei Municipal Ordinária Nº 10625 de 19 de Dezembro de 2002 que estabelece os níveis de ruído em função do tipo de ocupação da área e do horário, conforme Tabela 2 (CURITIBA, 2002). 


\section{Revista Produç@o}

Tabela 1 - Limites de tolerância para ruído contínuo ou intermitente

\begin{tabular}{|c|c|}
\hline NÍVEL DE RUÍDO, dB(A) & $\begin{array}{l}\text { MÁXIMA EXPOSIÇÃO DIÁRIA } \\
\text { PERMISSIIVEL }\end{array}$ \\
\hline 85 & 8 horas \\
\hline 86 & 7 horas \\
\hline 87 & 6 horas \\
\hline 88 & 5 horas \\
\hline 89 & 4 horas e 30 minutos \\
\hline 90 & 4 horas \\
\hline 91 & 3 horas e 30 minutos \\
\hline 92 & 3 horas \\
\hline 93 & 2 horas e 40 minutos \\
\hline 94 & 2 horas e 15 minutos \\
\hline 95 & 2 horas \\
\hline 96 & 1 hora e 45 minutos \\
\hline 98 & 1 hora e 15 minutos \\
\hline 100 & 1 hora \\
\hline 102 & 45 minutos \\
\hline 104 & 35 minutos \\
\hline 105 & 30 minutos \\
\hline 106 & 25 minutos \\
\hline 108 & 20 minutos \\
\hline 110 & 15 minutos \\
\hline 112 & 10 minutos \\
\hline 114 & 8 minutos \\
\hline 115 & 7 minutos \\
\hline
\end{tabular}

Fonte: Brasil (2009a). 
Tabela 2 - Níveis de Pressão Sonora Máximos

\begin{tabular}{|c|c|c|c|}
\hline ZONAS DE USO* & DIURNO & VESPERTINO & NOTURNO \\
\hline $\begin{array}{l}\text { ZR-1, ZR-2, ZR-3, ZR-B, ZR-AV, ZR-M, } \\
\text { APA-SARU, APA-SMRU }\end{array}$ & $55 \mathrm{~dB}(\mathrm{~A})$ & $50 \mathrm{~dB}(\mathrm{~A})$ & $45 \mathrm{~dB}(\mathrm{~A})$ \\
\hline $\begin{array}{l}\text { ZR-OC, ZR-SF, ZR-U, ZUC-II, ZT-MF, ZT- } \\
\text { NC, ZE-E, ZE-M, ZOO, SE-CC, SE-PS, SE-OI, } \\
\text { APA-ST }\end{array}$ & $60 \mathrm{~dB}(\mathrm{~A})$ & $55 \mathrm{~dB}(\mathrm{~A})$ & $50 \mathrm{~dB}(\mathrm{~A})$ \\
\hline $\begin{array}{l}\text { ZR-4, ZC, ZT-BR-116, ZUM, ZE-D, SE, SH, } \\
\text { SE-BR-116, SE-MF, SE-CF, SE-WB, SE-AC, } \\
\text { SE-CB,CONEC, SE-PE, SC-SF, SC-UM, SE- } \\
\text { NC, SEI, SEHIS, SE-LE, SEVC-PASSAÚNA, }\end{array}$ & $65 \mathrm{~dB}(\mathrm{~A})$ & $60 \mathrm{~dB}(\mathrm{~A})$ & $55 \mathrm{~dB}(\mathrm{~A})$ \\
\hline $\begin{array}{l}\text { SEVS-PASSAÚNA, APA-SS, Vias } \\
1 \text { e 2, Vias setoriais, Vias coletoras } 1\end{array}$ & & & \\
\hline ZS-1, ZS-2, ZES, ZI, ZEI-I (CIC), APA-SUE & $70 \mathrm{~dB}(\mathrm{~A})$ & $60 \mathrm{~dB}(\mathrm{~A})$ & $60 \mathrm{~dB}(\mathrm{~A})$ \\
\hline \multicolumn{4}{|c|}{$\begin{array}{l}\text { Os casos não contemplados nesta tabela, serão objeto de análise específica por parte da Secretaria } \\
\text { Municipal do Meio Ambiente }\end{array}$} \\
\hline \multicolumn{4}{|c|}{$\begin{array}{l}\text { Onde: APA-SARU - Setor de Alta Restrição de Uso; APA-SMRU - Setor de Média Restrição de } \\
\text { Uso; APA-ST - Setor de Transição; APA-SUE - Setor de Uso Esportivo; APA-SS - Setor de } \\
\text { Serviço; CONEC - Setor Especial Conector - Conectora 1,2,3,4, SC-SF - Setor Especial } \\
\text { Comercial Santa Felicidade; SC-UM - Setor Especial Comercial Umbará; SE - Setor Especial } \\
\text { Estrutural; SE-AC - Setor Especial da Av. Affonso Camargo; SE-BR-116 - Setor Especial da BR- } \\
\text { 116; SE-CB - Setor Especial da Rua Engenheiro Costa Barros; SE-CC - Setor Especial Centro } \\
\text { Cívico; SE-CF - Setor Especial da Av. Comendador Franco; SEHIS - Setor Especial Habitação de } \\
\text { Interesse Social; SEI - Setor Especial Institucional; SE-LE - Setor Especial Linhão do Emprego; } \\
\text { SE-MF - Setor Especial da Av. Mal. Floriano Peixoto; SE-NC - Setor Especial Nova Curitiba; SE- } \\
\text { OI - Setor Especial de Ocupação Integrada; SE-PE - Setor Especial Preferencial de Pedestres; SE- } \\
\text { PS - Setor Especial do Pólo de Software; SEVC-PASSAUNA -Setor Especial de Vias Coletoras; } \\
\text { SEVS-PASSAÚNA - Setor Especial de Vias Setoriais; SE-WB - Setor Especial da Av. Pres. } \\
\text { Wenceslau Braz; SH - Setor Histórico; ZC - Zona Central; ZOO - Zona de Ocupação Orientada; } \\
\text { ZE-D - Zona Especial Desportiva; ZE-E - Zona Especial Educacional; ZEI-I (CIC) - Zona } \\
\text { Especial de Indústria; ZE-M - Zona Especial Militar; ZES - Zona Especial de Serviços; ZI - Zona } \\
\text { Industrial; ZR-1 - Zona Residencial 1; ZR-2 - Zona Residencial 2; ZR-3 - Zona Residencial 3; ZR- } \\
\text { 4 - Zona Residencial 4; ZR-AV - Zona Residencial Alto da Glória; ZR-B - Zona Residencial Batel; } \\
\text { ZR-M - Zona Residencial Mercês; RZ-OC - Zona Residencial de Ocupação Controlada; ZUC-II - } \\
\text { Zona de Urbanização Consolidada; ZR-SF - Zona Residencial Santa Felicidade; ZR-U - Zona } \\
\text { Residencial Umbará; ZS-1 - Zona de Serviço 1; ZS-2 - Zona de Serviço 2; ZT-BR-116 - Zona de } \\
\text { Transição BR - 116; ZT-MF - Zona de Transição Av. Mal. Floriano Peixoto; ZT-NC - Zona de } \\
\text { Transição Nova Curitiba; Z-UM - Zona de Uso Misto; }\end{array}$} \\
\hline
\end{tabular}

Fonte: Curitiba (2002). 


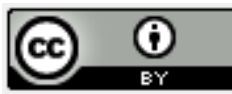

Alguns trechos da Lei Municipal Ordinária No 10625 da cidade de Curitiba pertinentes a esta monografia são apresentados a seguir (CURITIBA, 2002):

Art. $1^{\circ}$ - É proibido perturbar o sossego e o bem estar público com sons, ruídos e vibrações que causem incômodo de qualquer natureza ou que ultrapassem os limites fixados nesta lei.

Art. $2^{\circ}$. Para os efeitos desta lei, aplicam-se as seguintes definições:

I - SOM: vibração acústica capaz de provocar sensações auditivas.

II - RUÍDO: som capaz de causar perturbação ao sossego público ou efeitos psicológicos e fisiológicos negativos em seres humanos e animais.

IV - POLUIÇÃO SONORA: emissão de som ou ruído que seja, direta ou indiretamente, ofensivo ou nocivo à saúde, à segurança e ao bem estar da coletividade ou transgrida as disposições fixadas nesta lei.

\section{METODOLOGIA}

Levando-se em consideração a grande área abrangida pelo centro da cidade de Curitiba, o qual estima-se possuir cerca de 329,7 ha, escolheu-se para medição dos níveis de ruído, um total de 55 pontos. Destaca-se que as medições foram realizadas nas esquinas das ruas. Tais pontos encontram-se espalhados pelas avenidas Sete de Setembro e Visconde de Guarapuava e ruas Dr. Pedrosa, André de Barros, Pedro Ivo, José Loureiro e Emiliano Perneta, conforme mapa apresentado na Figura 2. 


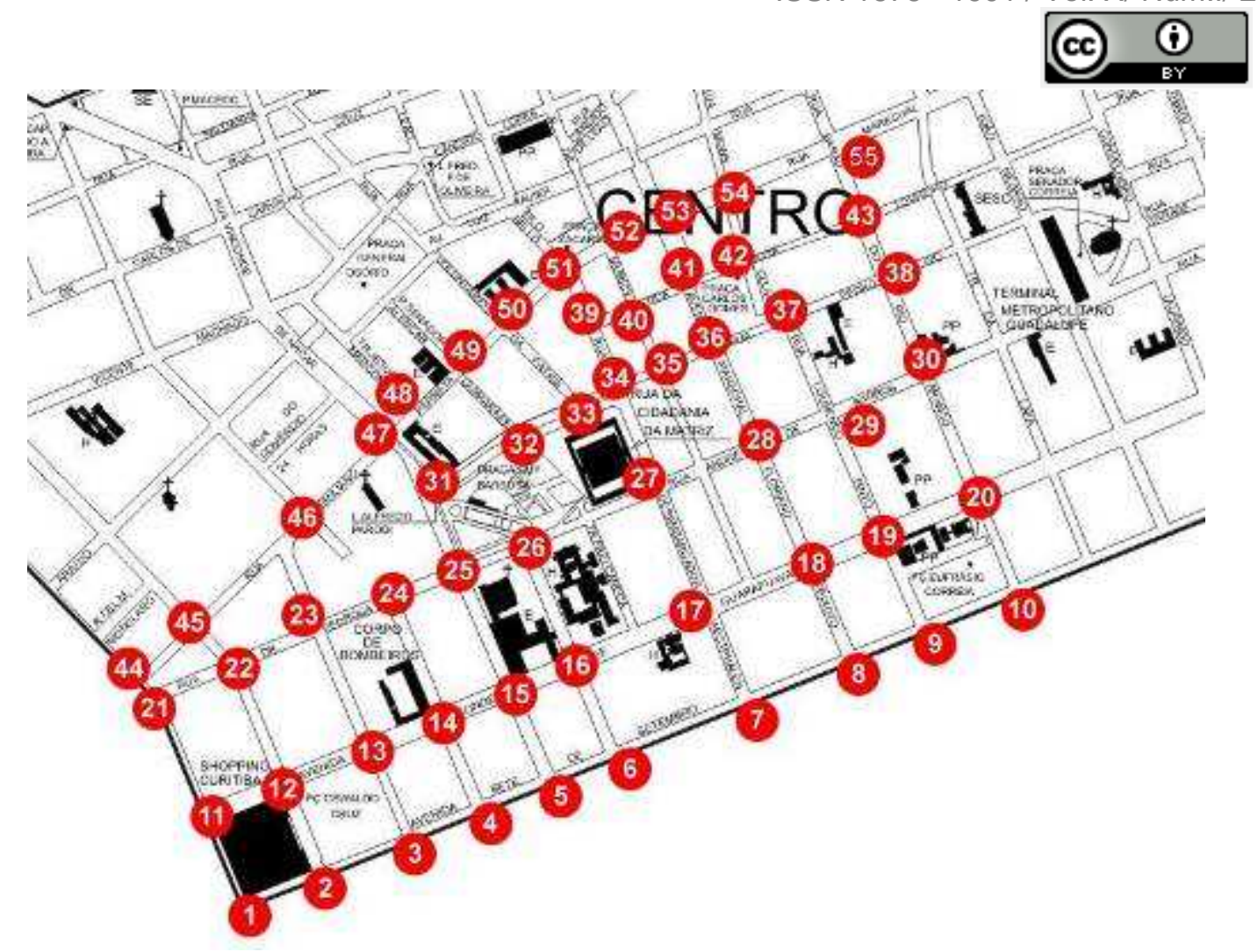

Figura 2 - Detalhamentos dos Pontos de Medição Fonte: Adaptado do IPPUC (2005).

As medições de ruído foram realizadas com um decibelímetro da marca Instrutherm, modelo DEC-5010, fabricado conforme norma ANSI S1.4, IEC-651 e IEC-804. Também foi utilizado um calibrador acústico do mesmo fabricante modelo CAL - 3000, para aferição do decibelímetro antes a após cada medição. Ambos os equipamentos possuíam certificados de calibração. O equipamento foi ajustado na curva "A" e com resposta lenta (slow), tudo conforme preconiza as normas. O equipamento utilizado possui uma precisão de $\pm 1,5 \mathrm{~dB}$.

As medições foram realizadas entre as 17:00 e 19:00 horas, sendo que para cada ponto foram realizadas 5 medições, calculando-se posteriormente uma média logarítmica do nível de ruído em cada ponto. Buscou-se realizar as medições neste horário, pois é o período do dia em que se têm os maiores níveis de ruído, ou seja, procurou-se caracterizar portanto o nível de ruído para cada ponto analisado, no pior horário do dia.

Com relação às condições, as medições foram realizadas a uma distância mínima de $1,5 \mathrm{~m}$ das paredes e outras superfícies refletoras e a uma altura de $1,2 \mathrm{~m}$ do solo. 


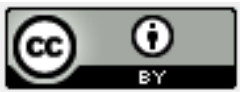

Evitou-se também a influência de sons não desejados como vento e ruído de interferências elétricas e condições climáticas extremas, uma vez que o nível de ruído pode ser influenciado por estas condições.

Para determinação do nível sonoro equivalente, de acordo com a norma, caso o ruído varie no tempo é recomendado que seja determinado o nível sonoro equivalente $\mathrm{L}_{\mathrm{eq}}(\mathrm{NBR}$ 10151, 2000).

Logo, para o cálculo do $\mathrm{L}_{\mathrm{eq}}$ fez-se uma análise da história temporal do nível sonoro em $\mathrm{dB}(\mathrm{A})$ baseada em registros analógicos ou digitais do nível sonoro. Para fins de estimativa determinou-se a distribuição estatística, observando-se as leituras do medidor do nível sonoro a intervalos de tempo, através de uma técnica de amostragem.

O nível sonoro equivalente foi calculado através da Equação 3 baseada no princípio de igual energia onde $\mathrm{L}_{\mathrm{i}}$ é o nível de pressão sonora lido a cada $5 \mathrm{~s}$, durante o tempo de medição do ruído e $n$ o número total de leituras.

$$
L_{e q}=10 * \log \frac{1}{n} \sum_{i=1}^{n} 10^{\frac{l i}{10}}
$$

Os valores de ruído obtidos foram comparados com aqueles limites estabelecidos pela Lei Municipal Ordinária no 10625 de 19 de dezembro de 2002, a qual estabelece um nível de ruído para a região central no período diurno de no máximo $65 \mathrm{~dB}(\mathrm{~A})$.

Após terem sido feitas todas as medições partiu-se para a confecção do mapa de ruído no qual se procurou representar por meio de cores as faixas de ruído presentes em cada região.

\section{RESULTADOS E DISCUSSÕES}

Após a realização das medições, obteve-se os níveis médios de ruído, estes obtidos em escala logarítmica, com um total de cinco medições para cada ponto.

\subsection{Análise de Ruído na Avenida Sete de Setembro}

Na Figura 3 são apresentados os valores de ruído obtidos para a Avenida Sete de Setembro. 
Ruido Avenida Sete de Setembro

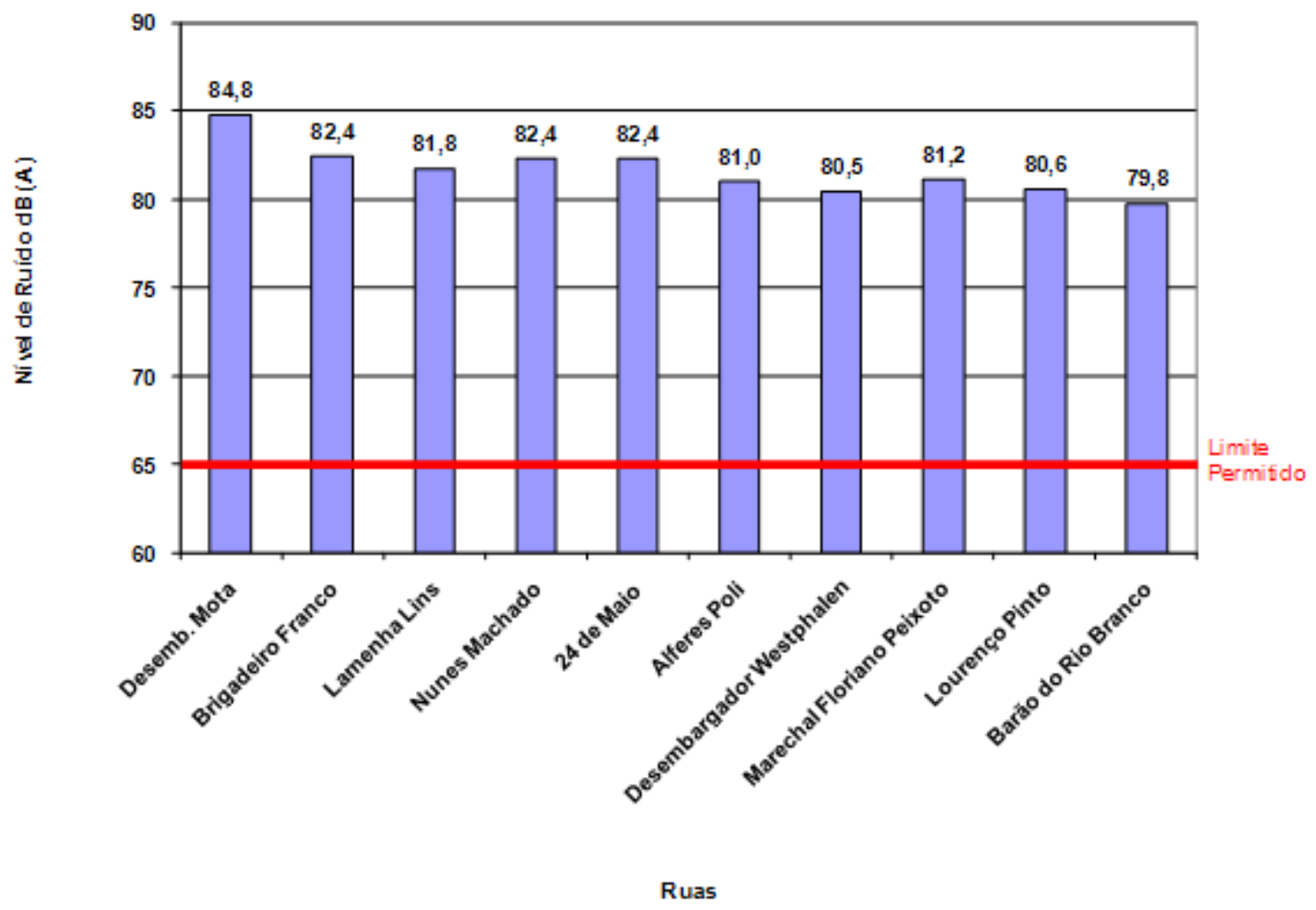

Figura 3 - Níveis de Ruído na Avenida Sete de Setembro

Analisando-se os níveis de ruído obtidos para a Avenida Sete de Setembro na Figura 3, nota-se que nos 10 pontos medidos, os valores obtidos superaram o indicado pela legislação municipal $(65 \mathrm{~dB}(\mathrm{~A}))$. Esta avenida apresentou um nível de ruído médio de 81,9 dB(A) o que representa $16,9 \mathrm{~dB}(\mathrm{~A})$ acima do estabelecido. O ponto que apresenta a maior média de ruído é o da esquina com a rua Desembargador Mota. Observa-se que o ruído médio foi obtido através de uma média logarítmica e não aritmética.

Observa-se ainda que em nenhum dos pontos observados ultrapassou-se o valor de 85 $\mathrm{dB}(\mathrm{A})$, que é o limite máximo permissível de ruído, segundo a NR-15, para uma exposição ocupacional de 8 horas diária. Dessa forma, conclui-se que para esta avenida em nenhum dos pontos avaliados ter-se-ia problemas quanto a insalubridade (NR-15), porém em todos existem problemas quanto ao conforto acústico do ambiente, pois todos os valores 


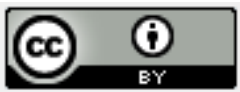

mensurados superaram a marca de $65 \mathrm{~dB}(\mathrm{~A})$, valor limite para conforto segundo a Lei Municipal Ordinária nº 10625 de 19 de dezembro de 2002.

\subsection{Análise de Ruído na Avenida Visconde de Guarapuava}

Na Figura 4 são apresentados os valores de ruído obtidos para a Avenida Visconde de Guarapuava.

Ruido A ven ida Visconde de Guarapuava

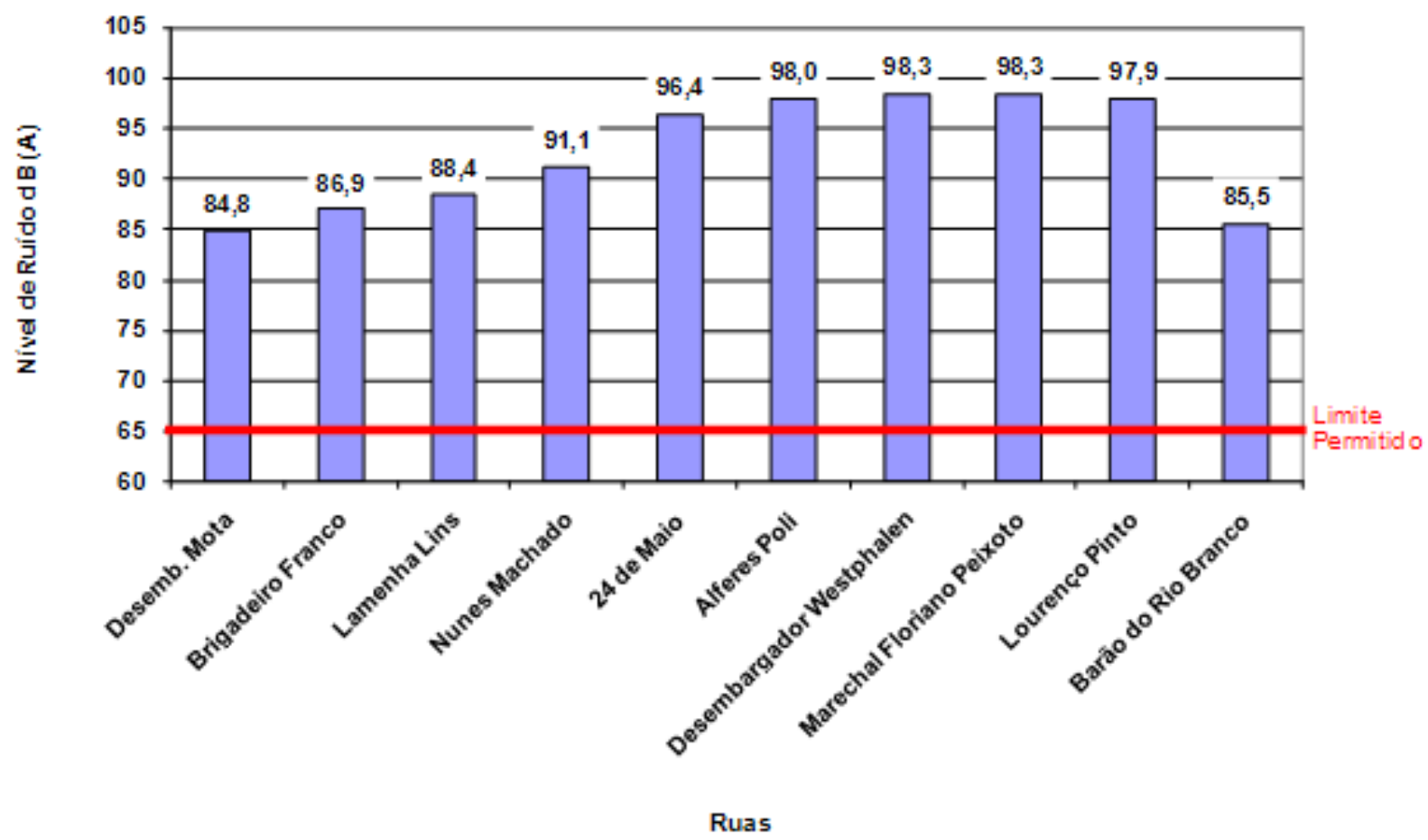

Figura 4 - Níveis de Ruído na Avenida Visconde de Guarapuava

De acordo com a Figura 4, observa-se que a Avenida Visconde de Guarapuava apresentou o maior nível médio de ruído $(95,2 \mathrm{~dB}(\mathrm{~A}))$ e o maior nível máximo medido de todos os pontos analisados (98,0 $\mathrm{dB}(\mathrm{A})$ na esquina com a rua Alferes Poli). Estes elevados valores de ruído nestes pontos podem ser explicados pelo elevado trânsito de ônibus e automóveis, visto que esta avenida apresenta seis pistas de tráfego.

Observa-se ainda que em apenas um dos pontos medidos o valor de ruído não superou os $85 \mathrm{~dB}(\mathrm{~A})$, que é o limite máximo permissível de ruído, segundo a NR-15, para uma exposição ocupacional de 8 horas diária. Dessa forma, conclui-se que para esta avenida em praticamente todos os pontos avaliados ter-se-ia problemas quanto a insalubridade (NR-15) e 
também problemas quanto ao conforto acústico do ambiente, pois todos os valores mensurados superaram a marca de $65 \mathrm{~dB}(\mathrm{~A})$, valor limite para conforto segundo a Lei Municipal Ordinária no 10625 de 19 de dezembro de 2002.

\subsection{Análise de Ruído nas Ruas Dr. Pedrosa / André de Barros}

Na Figura 5 são apresentados os valores de ruído obtidos para as Ruas Dr. Pedrosa e André de Barros. O valor médio de ruído observado foi de $76,4 \mathrm{~dB}(\mathrm{~A})$, sendo que este valor se encontra 11,4 $\mathrm{dB}(\mathrm{A})$ acima do permissível segundo a Lei Municipal de Curitiba quanto a ruído.

Ruído Rua Dr. Pedrosa/André de Barros

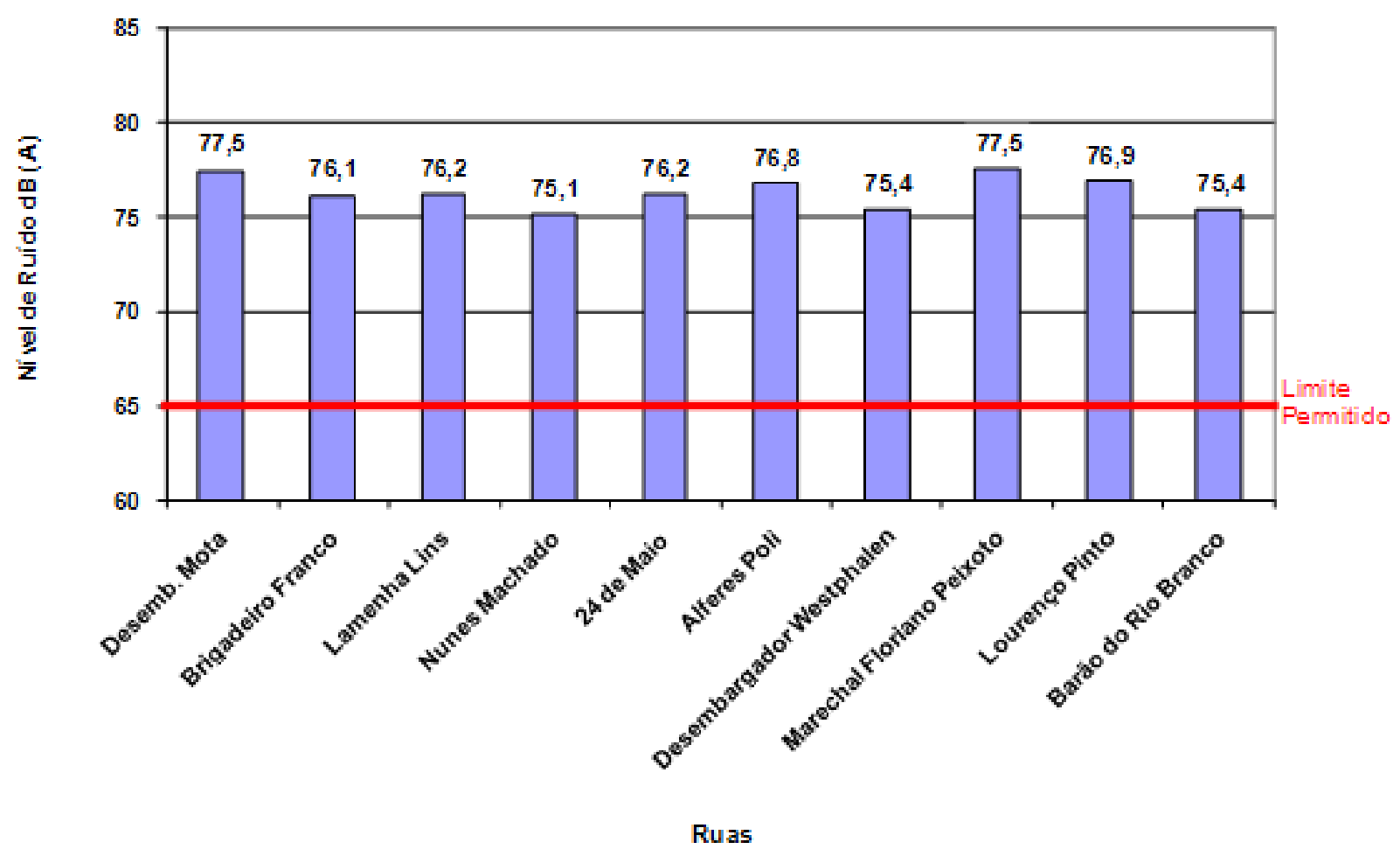

Figura 5 - Níveis de Ruído nas Ruas Dr. Pedrosa/André de Barros

Analisando-se a Figura 5 nota-se que todos os valores obtidos estão acima de 65 dB(A) (limite de ruído para conforto acústico) e abaixo de $85 \mathrm{~dB}(\mathrm{~A})$ (limite máximo de ruído para fins de pagamento de insalubridade). 


\subsection{Análise de Ruído na Praça Rui Barbosa}

Na Figura 6 são apresentados os valores de ruído obtidos para a Praça Rui Barbosa.

Ruído Praça Ruıi Earbosa

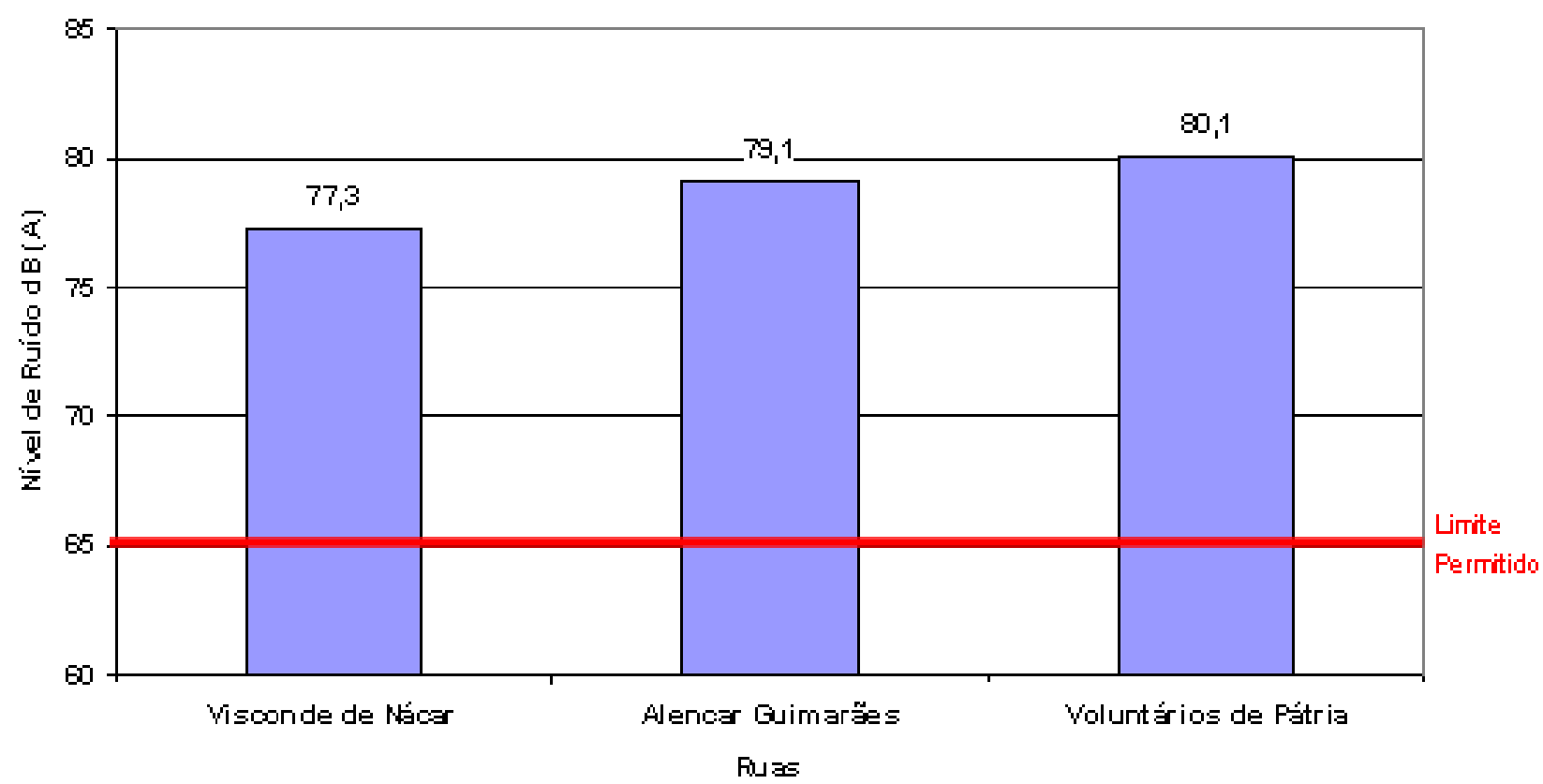

Figura 6 - Níveis de Ruído na Praça Rui Barbosa

Apesar do nível de ruído na Praça Rui Barbosa ser bastante influenciado pela presença de ônibus, o tráfego de automóveis nas Ruas Visconde de Nácar, Alencar Guimarães e Voluntários da Pátria não é tão intenso quanto na Avenida Visconde de Guarapuava, por exemplo, fazendo com que o nível médio de ruído de $79 \mathrm{~dB}(\mathrm{~A})$ apresente uma das menores diferenças entre o medido e o permitido $(13,9 \mathrm{~dB}(\mathrm{~A}))$.

Analisando-se a Figura 6 nota-se que todos os valores obtidos estão acima de 65 dB(A) (limite de ruído para conforto acústico) e abaixo de $85 \mathrm{~dB}(\mathrm{~A})$ (limite máximo de ruído para fins de pagamento de insalubridade).

\subsection{Análise de Ruído na Rua Pedro Ivo}

Na Figura 7 são apresentados os valores de ruído obtidos para a Rua Pedro Ivo. 
Ruído Rua Pedro Ivo

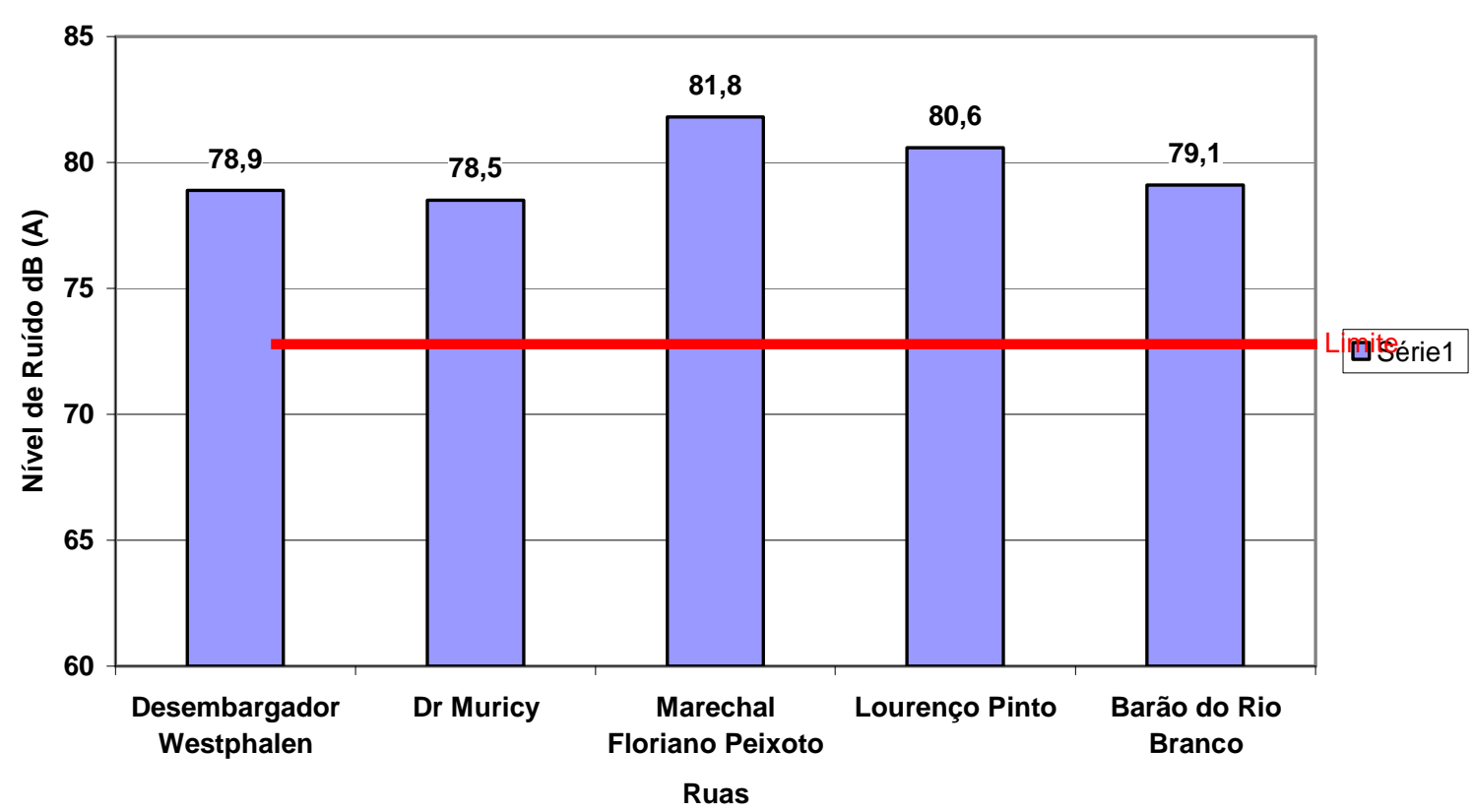

Figura 7 - Níveis de Ruído na Rua Pedro Ivo

Apresentando um nível médio de ruído de 80,0 dB(A) a rua Pedro Ivo caracteriza-se por ser uma via de acesso de ônibus ao terminal Guadalupe, porém é uma via estreita o que dificulta a passagem de grandes quantidades de automóveis ao mesmo tempo. Desta forma, este nível de ruído apresenta-se alto, porém compatível com a grande quantidade de ônibus e a lentidão do escoamento do tráfego.

Analisando-se a Figura 7 nota-se que todos os valores obtidos estão acima de 65 dB(A) (limite de ruído para conforto acústico) e abaixo de $85 \mathrm{~dB}(\mathrm{~A})$ (limite máximo de ruído para fins de pagamento de insalubridade).

\subsection{Análise de Ruído na Rua José Loureiro}

Na Figura 8 são apresentados os valores de ruído obtidos para a Rua José Loureiro.

Com as mesmas características da rua Pedro Ivo, a José Loureiro apresentou um nível médio de ruído muito similar a sua vizinha $(81,2 \mathrm{~dB}(\mathrm{~A}))$. Com as mesmas características de 
tamanho e sendo outra via de acesso ao terminal Guadalupe (chegada e saída de ônibus), é perfeitamente admissível esta semelhança de valores entre as ruas.

Riúdo Rùa José Loureiro

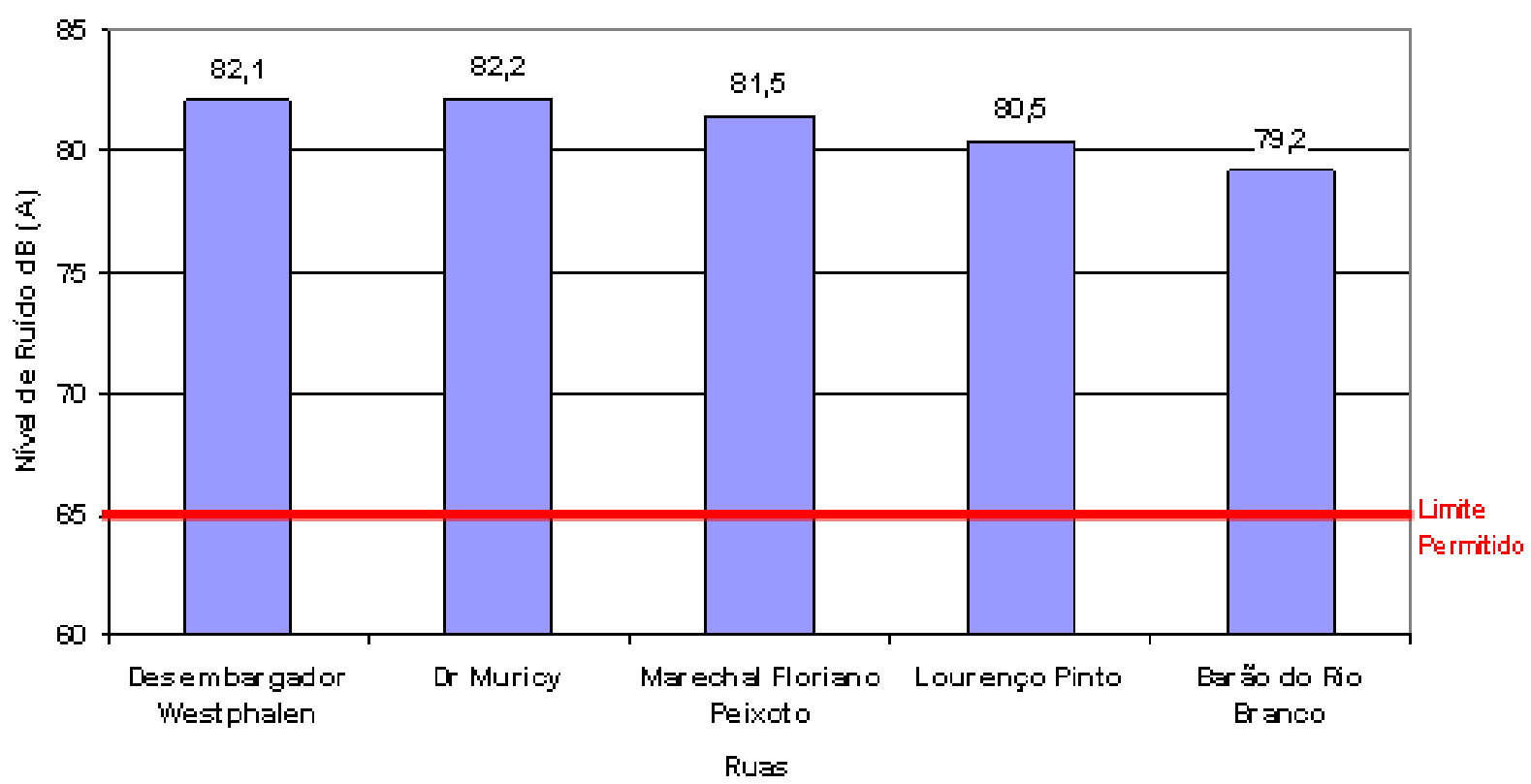

Figura 8 - Níveis de Ruído na Rua José Loureiro

Analisando-se a Figura 8 nota-se que todos os valores obtidos estão acima de 65 dB(A) (limite de ruído para conforto acústico) e abaixo de $85 \mathrm{~dB}(\mathrm{~A})$ (limite máximo de ruído para fins de pagamento de insalubridade).

\subsection{Análise de Ruído nas Ruas Emiliano Perneta / Marechal Teodoro}

Na Figura 9 são apresentados os valores de ruído obtidos para as Ruas Emiliano Perneta e Marechal Deodoro.

Com um nível alto de ruído (média de 85,9 dB(A)) as ruas Emiliano Perneta e Marechal Deodoro apresentam um intenso tráfego de veículos, porém, com pouca presença de ônibus. Nestas ruas ocorre a característica inversa das Ruas José Loureiro e Pedro Ivo, apresentando um tráfego mais rápido devido principalmente a quantidade de pistas de rodagem.

Analisando-se a Figura 9 observa-se ainda que em 8 dos 12 pontos medidos o valor de ruído não superou os $85 \mathrm{~dB}(\mathrm{~A})$, que é o limite máximo permissível de ruído, segundo a NR- 


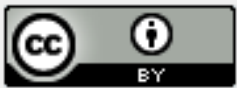

15, para uma exposição ocupacional de 8 horas diária. Dessa forma, conclui-se que para esta rua em alguns dos pontos avaliados ter-se-ia problemas quanto a insalubridade (NR-15). E em todos os pontos existem problemas quanto ao conforto acústico do ambiente, pois todos os valores mensurados superaram a marca de $65 \mathrm{~dB}(\mathrm{~A})$, valor limite para conforto segundo a Lei Municipal Ordinária no 10625 de 19 de dezembro de 2002.

Ruído Rusa Emiliano Perneta/Marechal Deodoro

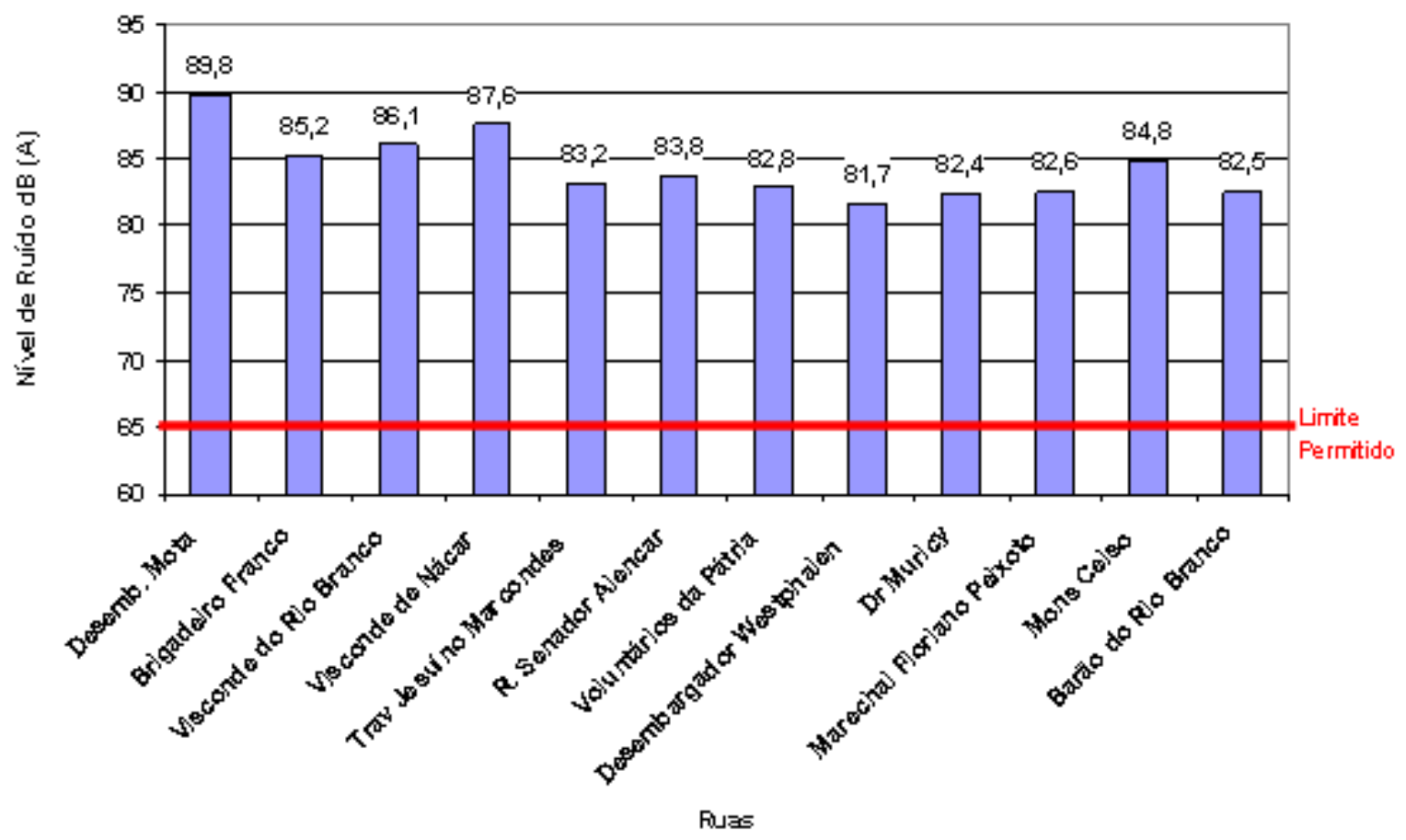

Figura 9 - Níveis de Ruído nas Ruas Emiliano Perneta/André de Barros

\subsection{Análise comparativa entre os níveis de ruído entre ruas/avenidas}

A tabela 3 apresenta uma avaliação de todas as ruas e avenidas medidas e uma ordenação de acordo com o ruído médio, levando-se sempre em consideração os níveis de ruído recomendados pela Lei Municipal No 10625. A tabela 4 apresenta uma avaliação da área central com os 55 pontos medidos. 
Tabela 3 - Avaliação dos Níveis Sonoros Medidos (Ruas e Avenidas)

\begin{tabular}{|c|c|c|c|c|}
\hline & Rua/Avenida & $\begin{array}{l}\text { Ruído } \\
\text { Médio, } \\
\mathrm{dB}(\mathrm{A})\end{array}$ & $\begin{array}{l}\text { Diferença entre } \\
\text { medido e } \\
\text { permitido, } \mathrm{dB}(\mathrm{A})\end{array}$ & $\begin{array}{l}\text { Nível Máximo } \\
\text { Medido, dB(A) }\end{array}$ \\
\hline 1 & Visconde de Guarapuava & 995,2 & 27,5 & 99,6 \\
\hline 2 & Alferes Poli & 93,3 & 28,3 & 99,6 \\
\hline 3 & 24 de Maio & 91,8 & 26,8 & 98,4 \\
\hline 4 & Lourenço Pinto & 91,2 & 26,2 & 99,1 \\
\hline 5 & Marechal Floriano Peixoto & 91,0 & 26,0 & 99,1 \\
\hline 6 & Desembargador Westphalen & 90,9 & 25,9 & 99,3 \\
\hline 7 & Visconde de Nácar & 87,6 & 22,6 & 89,2 \\
\hline 8 & Nunes Machado & 86,9 & 21,9 & 93,3 \\
\hline 9 & Desembargador Mota & 86,1 & 21,1 & 93,8 \\
\hline 10 & Visconde do Rio Branco & 86,1 & 211 & 87,5 \\
\hline 11 & Emiliano Perneta/Marechal Deodoro & 85,1 & 20,1 & 93,8 \\
\hline 12 & Mons. Celso & 84,8 & 19,8 & 86,7 \\
\hline 13 & Lamenha Lins & 84,7 & 19,7 & 89,1 \\
\hline 14 & Brigadeiro Franco & 84,2 & 19,2 & 88,2 \\
\hline 15 & Senador Alencar & 83,8 & 18,8 & 81,1 \\
\hline 16 & Trav. Jesuíno Marcondes & 83,2 & 18,2 & 85,0 \\
\hline 17 & Voluntários da Pátria & 82,8 & 17,8 & 82,0 \\
\hline 18 & Sete de Setembro & 81,9 & 16,9 & 87,4 \\
\hline 19 & Barão do Rio Branco & 81,4 & 16,4 & 91,2 \\
\hline 20 & Dr. Muricy & 81,3 & 16,3 & 83,5 \\
\hline 21 & José Loureiro & 81,2 & 16,2 & 83,4 \\
\hline 22 & Voluntários da Pátria & 80,1 & 15,1 & 82,0 \\
\hline 23 & Pedro Ivo & 80,0 & 15,0 & 83,9 \\
\hline 24 & Alencar Guimarães & 79,1 & 14,1 & 81,1 \\
\hline
\end{tabular}




\section{Revista Proctuço}

\begin{tabular}{|c|c|c|c|c|}
\hline 25 & Praça Rui Barbosa & 79,0 & 14,0 & 82,0 \\
\hline 26 & Visconde de Nácar & 77,3 & 12,3 & 89,2 \\
\hline 27 & Dr. Pedrosa/André de Barros & 76,4 & 11,4 & 79,9 \\
\hline
\end{tabular}

Tabela 4 - Avaliação dos Níveis Sonoros Medidos (Centro)

\begin{tabular}{||l|c|}
\hline \multicolumn{2}{|c|}{ Centro } \\
\hline \hline Pontos Medidos & 55 \\
\hline \hline Horário de Medição (horas) & $17: 00$ às 19:00 \\
\hline \hline $\begin{array}{l}\text { Pontos Acima do permitido segundo a Lei Municipal N } \\
10625(65 d B(A))\end{array}$ & 55 \\
\hline \hline Ruído Médio (dB(A)) & 87,7 \\
\hline \hline Média da Diferença entre medido e permitido (dB(A)) & 17,1 \\
\hline \hline Nível Máximo Medido dB((A)) & 99,6 \\
\hline \hline Nível Mínimo Medido dB((A)) & 73,2 \\
\hline \hline Leq Máximo Medido dB((A)) & 98,3 \\
\hline \hline Leq Mínimo Medido dB((A)) & 75,1 \\
\hline \hline
\end{tabular}

A figura 10 apresenta o mapa de ruído do bairro centro de acordo com a área analisada. Este tipo de mapeamento permite facilmente a identificação de regiões críticas bem como a variação de todos os níveis de ruído analisados. 


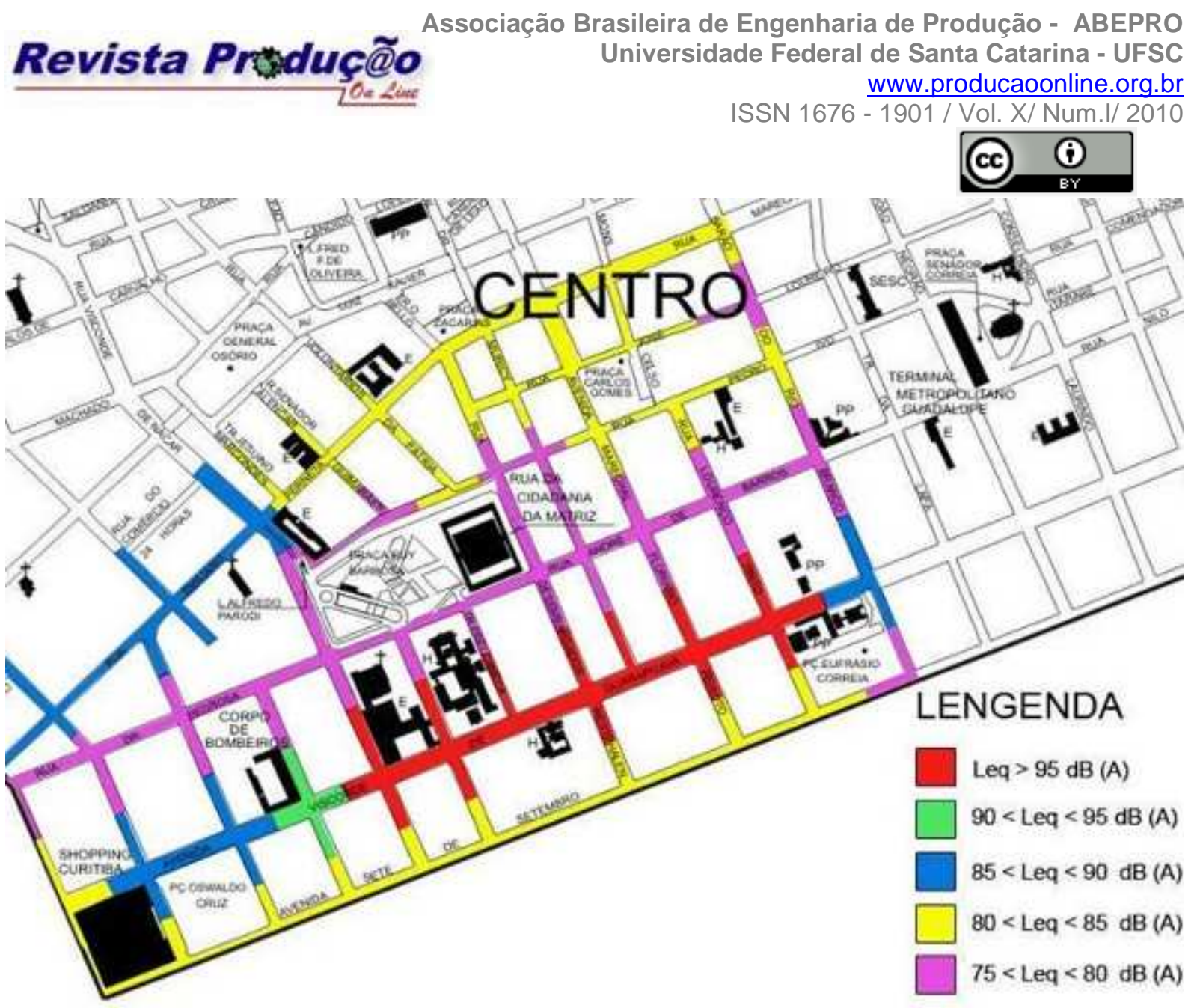

Figura 10 - Mapa de Ruído da Área Analisada do Bairro Centro

Fazendo-se uma análise da tabela 3 e figura 10 é possível realizar um agrupamento das ruas em função do nível de ruído apresentado.

As ruas/avenidas Visconde de Guarapuava, Alferes Poli, 24 de Maio, Lourenço Pinto, Marechal Floriano, Peixoto e Desembargador Westphalen apresentaram os maiores níveis médios de ruído. Esta característica justifica-se principalmente pelo intenso tráfego de veículos e ônibus e pela boa velocidade de escoamento facilitada principalmente por estas serem ruas largas e com mais de duas pistas de rodagem. É importante salientar que estes resultados devem ser aplicados somente aos pontos medidos, e não as demais extensões destas ruas. Nestas medições, a rua Alferes Poli, por exemplo, apresentou a segunda maior média de ruído $(93,3 \mathrm{~dB}(\mathrm{~A}))$, porém deve-se levar em consideração que a região desta rua medida serve de entrada para uma grande quantidade de ônibus que chegam na Praça Rui Barbosa.

As ruas/avenidas Visconde de Nácar, Nunes Machado, Desembargador Mota, Visconde do Rio Branco, Emiliano Perneta/Marechal Deodoro, Mons Celso, Lamenha Lins, Brigadeiro 


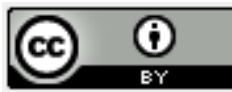

Franco, Senador Alencar, Travessa Jesuíno Marcondes, Voluntários da Pátria, Sete de Setembro, Barão do Rio Branco, Dr. Muricy, José Loureiro e Voluntários da Pátria apresentaram níveis de ruído entre 80,0 e 90,0 dB(A). Dentre as características destas ruas, tem-se um intenso trânsito de veículos, porém com uma menor quantidade de ônibus e uma velocidade de tráfego inferior ao primeiro grupo de ruas analisado.

O último grupo compreendido pelas ruas Pedro Ivo, Alencar Guimarães, Praça Rui Barbosa, Visconde de Nácar e Dr. Pedrosa/André de Barros, apresentou os menores níveis de ruído, entre 75 e $80 \mathrm{~dB}(\mathrm{~A})$. As duas primeiras ruas deste grupo têm como característica serem estreitas o contribui para um trânsito lento. Apesar de as ruas Visconde de Nácar e Dr. Pedrosa não serem escoadouros estreitos, no momento da medição havia grandes congestionamentos o que contribui para a baixa velocidade de passagem dos veículos.

\section{CONSLUSÕES}

De uma maneira geral, pode-se concluir que todos os 55 pontos analisados, compreendidos entre o horário das 17:00hs às 19:00hs, apresentaram níveis de ruído acima dos $65 \mathrm{~dB}(\mathrm{~A})$ estabelecidos pela lei Municipal Ordinária 10625 e como, durante as medições, não foram observadas outras importantes fontes de geração de ruídos, como canteiros de obra, tais níveis são atribuídos principalmente ao trânsito.

Se os valores de ruídos obtidos fossem comparados com os limites estabelecidos pela NR-15, ter-se-ia muitos pontos medidos nos quais os valores de ruído ultrapassariam o limite de $85 \mathrm{~dB}(\mathrm{~A})$ para 8 horas de exposição. Contudo vale a pena lembrar que as medições foram feitas durante um horário em que o ruído tende a ser maior, devido por exemplo ao tráfego intenso, e possivelmente em outros horários do dia estes valores de ruído tenderiam a ser menores, sendo que no período de 8 horas dificilmente se teria um ruído equivalente superior a $85 \mathrm{~dB}(\mathrm{~A})$.

Possíveis soluções para amenizar o problema seriam o controle dos níveis de ruídos emitido pelos escapamentos dos carros e uma maior fiscalização de motos e ônibus, pois são estes que, aparentemente, durante as medições aparentaram maiores emissões de ruído.

Conclui-se ainda que o mapa de ruído elaborado neste artigo tende a ser uma ferramenta extremamente interessante para o mercado imobiliário e para a Prefeitura, que teria uma 


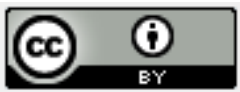

ferramenta gráfica a qual poderia utilizar para criar ou rever suas leis de zoneamento e uso do solo.

\section{Referências}

ASSOCIAÇÃO BRASILEIRA DE NORMAS TÉCNICAS. NBR - 10.151. Avaliação do Ruído em Áreas Habitadas, Visando o Conforto da Comunidade - Procedimento. Rio de Janeiro: ABNT, 2000. ASSOCIAÇÃO BRASILEIRA DE NORMAS TÉCNICAS. NBR - 10.152. Níveis de Ruído para Conforto Acústico. Rio de Janeiro: ABNT, 1987.

BERANEK, L. L. Sound and Vibration Control. New York. 1996. Instituto de Pesquisa e Planejamento Urbano de Curitiba: Curitiba em Dados. 2000. Disponível em: 〈http://ippucnet.ippuc.org.br/Bancodedados/Curitibaemdados/Curitiba_em dados_Pesquisa.asp〉. Acesso em: 01 de janeiro 2009.

BRASIL, Ministério do Trabalho e Emprego. Norma Regulamentadora NR-15 - Atividades e Operações Insalubres. Segurança e Medicina do Trabalho - Manual de Legislação Atlas. 63a . Edição, 2009a.

BRASIL, Ministério do Trabalho e Emprego. Norma Regulamentadora NR-17 - Ergonomia. Segurança e Medicina do Trabalho - Manual de Legislação Atlas. 63a . Edição, 2009 b.

CURITIBA, Lei $\mathbf{N}^{\mathbf{0}} \mathbf{1 0 6 2 5}$ de 19 de dezembro de 2002. Dispõe sobre ruídos urbanos, proteção do bem estar e do sossego público, revoga as Leis ns 8583, de 02 de janeiro de 1995, 8726, de 19 de outubro de 1995, 8986, de 13 de dezembro de 1996, e 9142, de 18 de setembro de 1997, e dá outras providências. Disponível em: 〈http://domino.cmc.pr.gov.br/contlei.nsf/>. Acesso em: 01 de janeiro 2009.

GERGES, S. N. Y. Ruído. Fundamentos e Controle. $2^{\text {a }}$ edição. Florianópolis: Editora Imprensa Universitária UFSC, 2000.

GERGES, S. N. Y. Ruído: Fundamentos e Controle. Florianópolis. 1992. 73. Disponível em: 〈http://domino.cmc.pr.gov.br/contlei.nsf/>. Acesso em: 01 de janeiro 2009.

GONÇALVES, V. S. B.; SENA, L.; CARVAHO, M.; SILVA, L. B. da. Ruído Ocupacional e a Inteligibilidade em Salas de Aula. In: II SIMPÓSIO SOBRE CONFORTO, EFICIÊNCIA E SEGURANÇA NO TRABALHO, 2005, João Pessoa. II Simpósio sobre Conforto, Eficiência e Segurança no Trabalho. João Pessoa: UFPB, 2005. v. Unico. p. 01-10.

IIDA, I. Ergonomia: projeto e produção. $2^{\text {a }}$ edição revisada e ampliada. São Paulo: Edgard Blücher, 2005.

INSTITUTO DE PESQUISA E PLANEJAMENTO URBANO DE CURITIBA. Mapas Digitais de Arruamento de Curitiba. 2005. Disponível em: 〈http://www.ippuc.org.br/informando/index_mapasarruamento.htm>. Acesso em: 01 de janeiro 2009.

LACERDA, A. B. M. de; MAGNI, C.; MORATA, T. C.; MARQUES, J. M.; ZANNIN, P. H. T. Ambiente Urbano e Percepção da Poluição Sonora. 2005. Disponível em: 〈http://www.scielo.br/scielo.php?script=sci_arttext\&pid=S1414-753X2005000200005 \&lang=pt $>$. Acesso em: 10 de Outubro 2009.

MOORE, Keith L.; DALLEY, Arthur F. Anatomia Orientada para Clínica. Rio de Janeiro, 2001. 


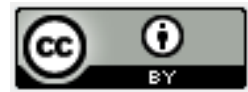

MORAES, A. G.; REGAZZONI, R. D. Perícia e avaliação de ruído e calor passo a passo - Teoria e prática. Rio de Janeiro. 2002.

SANTOS, T. M. M., RUSSO, I. P. A Prática da Audiologia Clínica. São Paulo: Cortez, 1993.

SILVA, Péricles. Acústica Arquitetônica e Acondicionamento de Ar. Belo Horizonte, 2002

ZANnIN, P. H. T.; SZEREMETTA, B. Avaliação da Poluição Sonora no Parque Jardim Botânico de Curitiba, Paraná, Brasil. Caderno Saúde Pública, n.19, p. 683-686. Rio de Janeiro: 2003.

ZANQUETA, Hugo F. B.; SOUSA, Luisa H. D. C. Avaliação de Ruído Comunitário na Área central de Maringá - PR. Maringá, 2006.

WORLD HEALth ORGANIZATION (WHO). Résumé D'orientation Des Directives De I'oms Relatives Au Bruit Dans I'environmental. 2003. Disponível em 〈http://www.who.int/homepage/primers $>$. Acesso em: $10 \mathrm{de}$ Outubro 2009.

Artigo recebido em 13/04/2009 e aceito para publicação em 12/03/2010 